\title{
Analysis of the Applicable Rate of Environmental Tax through Different Tax Rate Scenarios in China
}

\author{
Biao Hu ${ }^{1,2}$, Hongjia Dong ${ }^{1,2}$, Ping Jiang ${ }^{1,2, *}$ and Jingan Zhu ${ }^{1,2}$ \\ 1 Department of Environmental Science and Engineering, Fudan University, Shanghai 200433, China; \\ 18210740045@fudan.edu.cn (B.H.); 16210740034@fudan.edu.cn (H.D.); 19210740044@fudan.edu.cn (J.Z.) \\ 2 Tyndall Center, Fudan University, Shanghai 200433, China \\ * Correspondence: jiangping@fudan.edu.cn; Tel.: +86-21-3124-8915
}

Received: 8 April 2020; Accepted: 20 May 2020; Published: 21 May 2020

\begin{abstract}
Faced with increasing conflicts between economic and environmental development, it is extremely urgent to promote the green growth of enterprises. As an incentive environmental regulation measure, an environmental tax has been proven to effectively alleviate environmental problems and reduce corporate pollutant emissions. From the perspective of environmental tax equity and efficiency, this study collects more than 100,000 enterprises' pollutant-discharge and pollutant-discharge fee data from 4300 pollutant disposal enterprises in Yunnan Province, China in 2017. The study analyzes the marginal abatement cost (MAC) of water pollution and air pollution in key industries by using the MAC accounting method. Under the three scenarios of low, medium and high tax rates set by the study, the study evaluates the applicable tax rates of environmental tax of enterprises under different tax rates. The main findings of the study are: (1) the MAC of pollutants in various industries is quite different in different industries; (2) the environmental tax rate of 2018 is generally low and is not enough to encourage enterprises to reduce more pollution; (3) most enterprises will not invest a large amount of funds to carry out technological transformation for green production, without the government's mandatory environmental regulation measure. The study recommends that the government needs to increase the environmental tax rate, gradually approach the cost of corporate pollutant-treatment and force the technological transformation of enterprises. At the same time, the government itself needs to do a good job of tax neutrality, increase the compensation for environmental protection behaviors of enterprises, and encourage green development of enterprises. Finally, the taxation supervision should be strengthened, and the tax violations of enterprises should be checked strictly for avoidance of tax cuts against rules.
\end{abstract}

Keywords: environmental tax rate; tax efficiency; pollution control cost; enterprises; Yunnan Province; China

\section{Introduction}

Over the past decades, China's economy has been developing rapidly, but environmental damage is also very serious [1]. Therefore, we actively explore various measures to reduce pollutant emissions. Based on the timeline, there are command-control, economic incentive and voluntary awareness measures for environmental regulation. China mainly use command-control and economic incentive methods to deal with pollutant-discharge currently $[2,3]$. However, command-control environmental regulations have the disadvantages of high cost, low efficiency and low incentives. Countries had begun to actively explore other regulatory means [4]. In 1972, the Organization for Economic Cooperation and Development (OECD) countries promulgated the "polluter pays" principle, hoping to use environmental tax policies to internalize the behavior of public environmental resources, thereby restricting enterprises and individuals to protect the environment and achieve sustainable 
development [5]. With reference to the experience of other countries, China has also begun the exploration and practice of economic incentive environmental regulations for environmental protection since the $1970 \mathrm{~s}$ [6]. Since the pollutant-charge system was implemented on July 1, 2003 [7], China has brought in a standard collection policy of 0.6 yuan (Yuan is the unit of Chinese currency(RMB).)/PPE (RMB for per pollution equivalent) for air pollutants and 0.7 yuan/PPE for water pollutants. At the end of 2017, there are still 21 provinces with an environmental tax rate lower than 2.0 yuan/PPE. However, during this period, China's GDP has increased by more than seven times, and peoples' demands for a better life and a healthier living environment have continued to increase. It can be seen that the current environmental tax rate has been decoupled from the current status of China's development and cannot effectively play the true role of an environmental tax. As the environment is a non-exclusive public resource, only when the environmental resources are reasonably priced-and the environmental tax rate is higher than the company's industry's marginal abatement cost (MAC)—will enterprises have sufficient motivation to proactively reduce emissions. Otherwise it will lead to invalid allocation of resources and environmental problems [8].

At present, environmental taxation research focuses mainly on policy effects from the aspects of double dividends, employment benefits, the porter hypothesis and income redistribution. Tullock [9] first proposed the concept of double dividends, but Bovenberg and Mooij [10] pointed out that double dividends are not practical in production practices, which have strict conditions. At the same time, many scholars, such as Pearce [11] and Bossier [12], still support the notion that environmental tax can bring more employment opportunities to society. Moreover, based on research in South Africa [13], it was further pointed out that environmental taxes can reduce the urban-rural gap so that the distributed double dividend is established. The research on environmental taxes in China started late. Before 2017, the Environmental Protection Department levied the pollutant-discharge fee, since 2018, the pollutant-discharge fee has been replaced by the environmental tax which was levied by the tax bureau in China. Most scholars, such as Liu et al. [14], have focused on the introduction and paraphrasing of foreign literature and scholars such as Jin [15] has sinicized the experience of OECD countries. Some scholars, such as Li and Qin [5,16], have also used CGE, GREAT-E and other mathematical models to carry out quantitative analysis and have quantitatively set different tax rates for different industries according to pollution intensity so that pollution control can also take into account national economic growth and increase government revenue. In addition, from the perspective of who should be responsible for taxation, some scholars believe that a cost-sharing mechanism should be established between producers and consumers $[17,18]$. Although the current official statistical methods indicate that pollutant emissions are the responsibility of producers, many scholars have pointed out that consumers should also be responsible $[19,20]$.

From the point of view of literature reading, there are few quantitative studies at the provincial level on environmental tax research, especially research on the appropriate environmental tax rate for a specific region or province [21]. In this study, Yunnan Province, a representative province in the southwest of China, has been used as a case to collect data on the pollutant-discharge of 4300 enterprises; calculate the MAC in different industries; set three tax rate scenarios, low, medium and high; and evaluate the proportion of environmental taxes in the company's annual output value. Moreover, suggestions for the implementation of environmental tax policies have been put forward. As the data and volume of the research involved in this study are large and time-effective, this study has a certain representativeness of the evaluation of the effect of implementation of environmental tax in Southwest China; At the same time, empirical research on incentive environmental policies such as environmental taxes has also been expanded and strengthened. 


\section{Research Method}

\subsection{Theoretical Basis}

Each unit of pollutant-discharge will cause certain damage to nature. With the increase of pollutant-discharge, the damage to nature will gradually increase, showing an increasing effect of marginal external damage. According to Pigou's externality theory, environmental tax should bridge the gap between marginal external damage cost (MDC) and corporate MAC. Under the premise of abiding by laws and regulations, as economic organizations with the goal of making profits, enterprises must chase the maximization of benefits. Considering the impacts on both economy and employment, there should be a suitable certain degree of reduction of emissions of pollutants for enterprises. It is the minimization of the total social cost function Tcost $=$ MDC + MAC within the range allowed by the policy. Therefore, in the case of meeting the environmental protection department's emission standards, companies will only take the initiative to reduce emissions if the MAC is lower than is the environmental tax rate. As shown in Figure 1, find the first and second derivatives of MAC and MDC, respectively, as $\mathrm{MDC}$ ' $<0, \mathrm{MDC}^{\prime}$ '>0; $\mathrm{MAC}^{\prime}>0, \mathrm{MAC}$ " $>0$; as the emission reduction progresses, the emission reduction concentration continues to decline, the MAC continues to accelerate and increase and MDC continues to slow down. Tcost decreases at first and then increases. When $\mathrm{MDC}=\mathrm{MAC}=\mathrm{P}$, Tcost is at the minimum state the pollution reduction amount is at the optimal pollution reduction amount $Q^{*}$ point. However, it is difficult to calculate the cost of pollutant damage to an enterprise, and it is difficult to calculate the level of damage caused by the discharge of different pollutants to a certain administrative area. The set value of the environmental tax rate should be as close as possible to the marginal pollution treatment cost corresponding to the emission reduction standard. If the tax rate is set too low at the $\mathrm{T}^{\prime}$ point, the enterprise will begin to pay environmental taxes when the reduction of emissions reaches the $\mathrm{T}^{\prime}$ point corresponding to the reduction point and save the Acost. If the tax rate is set too high at the $T^{\prime \prime}$ point, the enterprise will continue to implement emission reduction, if Bcost is more than the company's emission reduction costs. That will affect the normal operation of the enterprise. Therefore, studying the MAC of enterprises is of vital importance in determining the environmental tax rate of the administrative region [22], at the same time encourage companies to reduce pollutant emissions.

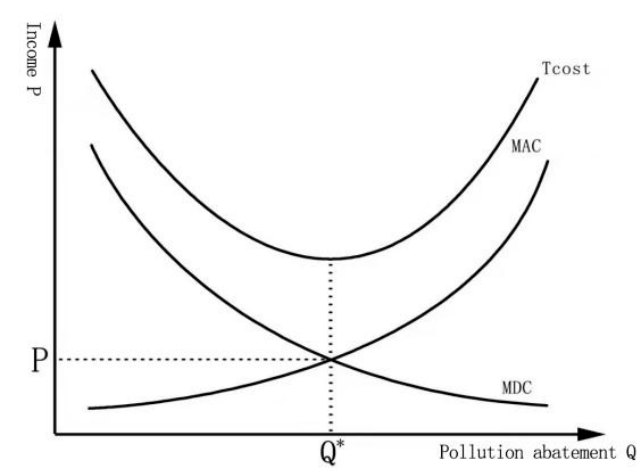

(a)

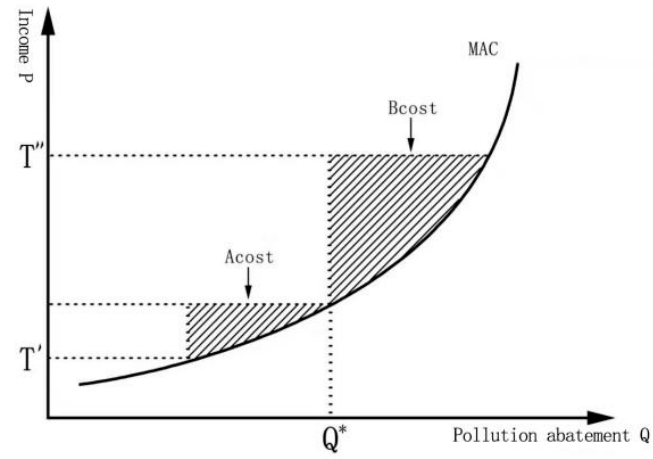

(b)

Figure 1. Principles for determining the optimal amount of pollutant reduction. (a) Marginal total cost curve of pollution abatement; (b) Optimal point of amount of pollution abatement.

\subsection{Pollution Treatment Cost Accounting Method}

The cost of pollutant-treatment consists of two main parts: the initial construction cost and the operation cost. The construction and installation costs mainly include equipment purchase, engineering construction, installation costs and technical service fees. The operating costs mainly 
include labor wages, pharmaceuticals, maintenance costs and material loss costs. The formula is expressed as follows:

$$
C_{\text {total cost }}=\left(C_{\text {construction and installation }}+C_{\text {operation }}\right) / Q_{\text {reduction of pollutants }}
$$

With reference to "economics of industrial pollution in China" [23], the cost reduction function for the pollution control of the $\mathrm{i}$-th plant that deals with $\mathrm{n}$ kinds of pollutants is:

$$
C_{i}=f\left(W_{i}, \frac{E_{\text {in }}}{I_{\text {in }}}, M_{i}, X_{i}\right)
$$

where $C_{i}$ is the total annual cost of end-of-pipe abatement for the plant $i . M_{i}$ is the cost in area where plant $i$ is located. $W_{i}$ is the total annual waste water or waste gas volume for the plant $i . E_{\text {in }}$ and $I_{\text {in }}$ are the vector of effluent/influent ratios for $\mathrm{n}$ pollutants, which can be interpreted either as concentration ratios or volume ratios.

Calculate the pollution control costs of enterprises by industry. After removing the discrete data, calculate the pollution control costs of each key industry. Finally, calculate the MAC of the province's atmospheric and water emission according to the weighted average method. The industry classification of this article is based on the industry classification of "China environmental statistics yearbook."

Conversion formula for pollution equivalent number is:

$$
E_{i}=D_{i} / B_{i}
$$

where $E_{i}$ is the pollution equivalent of a pollutant. $D_{i}$ is the discharge of this pollutant. $B_{i}$ is the emission equivalent of the pollutant.

Average abatement cost accounting method is:

$$
P_{\text {water } / a i r}=\sum_{j=1}^{10} P_{j} \cdot \alpha_{j}
$$

where $P_{\text {water } / a i r}$ is the water or air pollution average treatment cost. $P_{j}$ is the average treatment cost of industry contaminants. $\alpha_{j}$ is the percentage of pollutants discharged by $j$ industry. $j$ is the different industry.

The calculation method of marginal pollutant-treatment cost is:

$$
C=e^{\alpha_{0}} W^{\alpha_{1}+\alpha_{2} \log W \prod_{j=1}^{N}\left[\frac{E_{j}}{I_{j}}\right]_{i}}
$$

The corresponding marginal processing cost function can be expressed as:

$$
\frac{\partial C}{\partial E_{j}}=\frac{\beta_{i}}{E_{j}} e^{\alpha_{0}} W^{\alpha_{1}+\alpha_{2} \log W \prod_{j=1}^{N}\left[\frac{E_{j}}{I_{j}}\right]_{i}^{\beta_{i}}}
$$

The marginal pollution control costs by industry are:

$$
\partial P_{j}=\frac{\partial C_{j}}{\partial E_{j}}=\sum P_{j} \cdot \alpha_{j} \cdot \lambda_{j}
$$

where $\lambda_{j}$ is $j$ the industry marginal pollution control cost to average control cost ratio. $\alpha_{0}, \alpha_{1}, \alpha_{2}, \beta_{i}$ are constants and will change as the industry changes. 


\subsection{Calculation Method of Output Value Impact Rate}

To evaluate the impact on the burden of enterprises under different schemes, the output value impact rate evaluation method is used to test the pressure elasticity of different tax amounts on polluting units to find the distribution of enterprises with low and high impact.

The accounting method for the impact rate of total output value of an enterprise is:

$$
R_{i}=T_{i} / O V_{i}
$$

where $R_{i}$ is the impact rate of environmental tax output value under different schemes. $T_{i}$ is the total amount of environmental taxes paid by sewage units. $O V_{i}$ is the output value produced by sewage units.

Using the result of Equation (8), combined with the current environmental tax rate, as the basis for setting three scenarios of low, medium and high tax rates, to calculate and evaluate corporate burdens at different tax rate scenarios.

\subsection{Case Study}

The Yunnan Province is an ecologically challenged and underdeveloped province in western China. Rapid economic and industrial development in recent years has caused tremendous damage to the environment. Taking Yunnan as a case is representative. A literature review shows that there is a lack of research on environmental tax in the underdeveloped region of western China [24]. In addition, research data (enterprise data and environmental tax data) in Yunnan are sufficient.

\subsection{Data Sources}

Multi-level information data of environmental tax were collected, and interviews were conducted with Environmental Protection Agency, Taxation Bureau and taxpayers at three different government levels in Yunnan. These revealed the urgency and problems of implementing environmental tax, the shortcomings of implementation of environmental tax collection and management and policy recommendations. Enabling suggestions to be made based on analysis and evaluation. At the same time, we obtained data on pollutant-discharge charges in 2017 from Yunnan Province's 4300 companies and environmental tax data for 2018, that gives important support for improving the implementation of environmental taxes. In view of the fact that Yunnan Province has already set the minimum charging standards for waste gas and waste water pollution discharge from 2012 to 1.2 yuan/PPE and 0.7 yuan/PPE to 1.2 yuan/PPE and 1.4 yuan/PPE. Because of the policy of shifting fee to tax, which means the rates of pollutant-discharge fee and environmental tax are equal, so the newly levied environmental tax are still levied at the price of waste gas and waste water at 1.2 yuan/PPE and 1.4 yuan/PPE. The subsequent pollutant-discharge situation still has strong timeliness and reference value. Other data comes from the "China statistics yearbook" [25], the "China environmental statistics yearbook" [26] and wind database.

\subsection{Data Processing}

There are 4300 pollutant-discharge units in this sample and more than 100,000 pieces of data. There is a large amount of discrete data from calculating the average governance cost of the enterprise. For example, there are pollutant-discharge units that cost tens of thousands of yuan/PPE, whereas some are 0 yuan/PPE. There are obvious differences in the unit treatment costs of pollutants from some pollutant-discharge units. Therefore, using SPSS software and the boxplot method to remove the discrete data, we finally obtain valid data for 3390 pollutant-discharge companies and use the data to calculate the average MAC of each industry. 


\section{Results}

\subsection{Estimation of Pollutant-Treatment Costs}

After removing the discrete data, the above equations are used to calculate the average cost of pollution control for different key industries in Yunnan. Finally, Equation (7) is used to obtain the MAC of pollutants in each key industry. The results are shown in Tables 1 and 2:

Table 1. Costs of water pollution control in key industries in Yunnan Province in 2017.

\begin{tabular}{|c|c|c|c|c|c|}
\hline No. & Industry Type & $\begin{array}{c}\text { Average } \\
\text { Treatment Cost } \\
\text { (yuan/PPE) }\end{array}$ & $\begin{array}{c}\text { MAC } \\
\text { (yuan/PPE) }\end{array}$ & $\begin{array}{l}\text { Percentage of Total } \\
\text { Pollutant Emissions } \\
\text { in Various Industries }\end{array}$ & MAC Index ${ }^{1}$ \\
\hline 1 & $\begin{array}{l}\text { chemical products' } \\
\text { manufacturing }\end{array}$ & 14.44 & 17.33 & $16.9 \%$ & $37.66 \%$ \\
\hline 2 & Mining industry & 7.90 & 9.48 & $12.9 \%$ & $15.68 \%$ \\
\hline 4 & $\begin{array}{l}\text { Non-metallic mineral } \\
\text { products industry }\end{array}$ & 36.96 & 44.35 & $2.0 \%$ & $11.44 \%$ \\
\hline 5 & $\begin{array}{l}\text { Agricultural and sideline food } \\
\text { processing industry }\end{array}$ & 2.17 & 2.60 & $31.0 \%$ & $10.41 \%$ \\
\hline 6 & $\begin{array}{l}\text { Liquor, beverage and refined } \\
\text { tea manufacturing }\end{array}$ & 1.87 & 2.24 & $7.2 \%$ & $2.06 \%$ \\
\hline 9 & $\begin{array}{l}\text { Petroleum processing, } \\
\text { coking and nuclear fuel } \\
\text { processing industries }\end{array}$ & 0.85 & 1.02 & $1.9 \%$ & $0.26 \%$ \\
\hline 10 & Others & 5.71 & 6.85 & $8.2 \%$ & $7.20 \%$ \\
\hline \multicolumn{3}{|c|}{$\begin{array}{c}\text { The average cost of water pollution treatment in the } \\
\text { Yunnan is } 6.48 \text { yuan/PPE }\end{array}$} & \multicolumn{3}{|c|}{$\begin{array}{c}\text { Provincial marginal cost of water pollution treatment } \\
\text { is } 7.78 \text { yuan/PPE }\end{array}$} \\
\hline
\end{tabular}

Table 2. Air pollution control costs of key industries in Yunnan Province in 2017.

\begin{tabular}{|c|c|c|c|c|c|}
\hline No. & Industry Type & $\begin{array}{c}\text { Average } \\
\text { Treatment Cost } \\
\text { (yuan/PPE) }\end{array}$ & $\begin{array}{c}\text { MAC } \\
\text { (yuan/PPE) }\end{array}$ & $\begin{array}{l}\text { Percentage of Total } \\
\text { Pollutant Emissions } \\
\text { in Various Industries }\end{array}$ & MAC Index \\
\hline 1 & $\begin{array}{l}\text { Non-metallic mineral } \\
\text { products' industry }\end{array}$ & 6.38 & 10.21 & $35.1 \%$ & $43.07 \%$ \\
\hline 2 & $\begin{array}{l}\text { Ferrous metal smelting } \\
\text { and rolling }\end{array}$ & 7.81 & 12.50 & $13.4 \%$ & $20.13 \%$ \\
\hline 3 & $\begin{array}{l}\text { Chemical raw materials and } \\
\text { products' manufacturing }\end{array}$ & 3.04 & 4.86 & $13.6 \%$ & $7.94 \%$ \\
\hline 4 & $\begin{array}{l}\text { Petroleum processing, } \\
\text { coking and nuclear fuel } \\
\text { processing industries }\end{array}$ & 9.40 & 15.04 & $3.4 \%$ & $6.15 \%$ \\
\hline 5 & $\begin{array}{l}\text { Non-ferrous metal smelting } \\
\text { and rolling processing } \\
\text { industry }\end{array}$ & 1.92 & 3.07 & $11.7 \%$ & $4.32 \%$ \\
\hline 6 & $\begin{array}{l}\text { Electricity, heat production } \\
\text { and supply }\end{array}$ & 1.56 & 2.50 & $9.9 \%$ & $2.97 \%$ \\
\hline 7 & $\begin{array}{l}\text { Liquor, beverage and refined } \\
\text { tea manufacturing }\end{array}$ & 11.36 & 18.18 & $1.2 \%$ & $2.62 \%$ \\
\hline 8 & Mining industry & 5.76 & 9.22 & $2.3 \%$ & $2.55 \%$ \\
\hline 9 & $\begin{array}{l}\text { Agricultural and sideline food } \\
\text { processing industry }\end{array}$ & 1.92 & 3.07 & $3.6 \%$ & $1.33 \%$ \\
\hline 10 & Others & 8.32 & 13.31 & $5.7 \%$ & $9.12 \%$ \\
\hline \multicolumn{3}{|c|}{$\begin{array}{l}\text { The average cost of air pollution treatment in Yunnan is } \\
\qquad 5.20 \text { yuan/PPE }\end{array}$} & \multicolumn{3}{|c|}{$\begin{array}{l}\text { Provincial marginal cost of air pollution } \\
\text { control } 8.32 \text { yuan/PPE }\end{array}$} \\
\hline
\end{tabular}


It can be seen from table above that the average costs of pollution control for different industries are significantly different, both for water pollutants and for air pollutants. For water pollutants in Yunnan, although the non-metallic mineral products industry's MAC are as high as 44.35 yuan, the industry's contribution to the average pollution control cost of Yunnan is not significant due to its lower total pollution discharge. Conversely, the pollution control costs, and emissions of chemical raw materials and chemical products' manufacturing are relatively high, contributing $38 \%$ to the average cost of water pollution control in the province.

\subsection{Evaluation of the Burden of Enterprises on Different Tax Rates}

\subsubsection{Tax Rate Scenario Setting}

With reference to the research of Ge et al. [27], combined with the actual situation in Yunnan, this study has set low, medium and high scenarios with different tax rates, as shown in Table 3 . We assume that companies' pollution discharge behavior will not change after the tax reform.

Table 3. Different scenarios for environmental tax collection.

\begin{tabular}{ccccc}
\hline Scenarios & $\begin{array}{c}\text { Water Pollutant } \\
\text { Tax (yuan/PPE) }\end{array}$ & $\begin{array}{c}\text { Air Pollutant Tax } \\
\text { (yuan/PPE) }\end{array}$ & $\begin{array}{c}\text { MAC in Yunnan } \\
\text { Province (yuan/PPE) }\end{array}$ & Description \\
\hline Low scenario & 1.4 & 1.2 & Water pollutants: 7.78 & $\begin{array}{c}\text { Consistent with the } \\
\text { environmental tax rate of } \\
\text { 2018 and pollutant-discharge } \\
\text { fee standard of 2017 } \\
\text { Consistent with the }\end{array}$ \\
Medium scenario & 3.5 & 2.8 & Air Pollutants: 8.32 & $\begin{array}{c}\text { environmental tax rate of 2019 } \\
\text { Slightly higher than MAC of } \\
\text { Yunnan for water } \\
\text { and air pollutants }\end{array}$ \\
\hline
\end{tabular}

The low scenario is based on the consideration of the overall idea of implementing "tax-shifting" of environmental tax at the national level. The tax standard of this scenario is consistent with the pollutant-discharge fee in Yunnan Province since 2012 and the implementation effects in all aspects are basically the same as those before 2018. The implementation effect of fee is equivalent and the impact in all aspects is also minimal. This is to test the impacts of different collection and management departments on the actual collection of tax in the same situation.

The medium scenario is based on consideration of environmental tax to promote reduction of corporate pollution. The applicable tax amount of this plan is 2.5 times of the previous pollutant charge rate (2.5 times of 2018). This is equal to the environmental tax rate implemented on medium-scenario industries in Yunnan Province in 2019, which is higher than that of some industries in Yunnan Province. The average cost of pollution treatment is used to predict the impact of the new tax rate on various polluting enterprises in Yunnan Province.

In the high scenario, environmental taxation is an effective approach to force enterprises to vigorously promote pollution reduction. Under this scenario, the environmental tax rate is already higher than the average MAC of the enterprises. The price lever is used to force the enterprises to choose to pay less tax and increase their pollution control facilities. Upgrading and transformation will gradually realize near-zero emissions by enterprises. At the same time, this scenario provides a theoretical basis for further improvement of environmental tax rates in the future.

\subsubsection{Enterprise Burden Measurement}

This article uses the ratio of environmental tax to the total output value of an enterprise as a measure of the burden of the enterprise and defines it as tax-output ratio impact (TORI). According to Table 3, under the three different tax rate scenarios and calculated by Equation (8), the TORI of 3390 enterprises are made into three scatter-plots as Figures $2-4$. Simultaneously calculate the number 
of TORI enterprises in different levels and their changing trends under different tax rate scenarios, get Table 4 to evaluate the burden of different tax rate scenarios on the production and operation of enterprises.

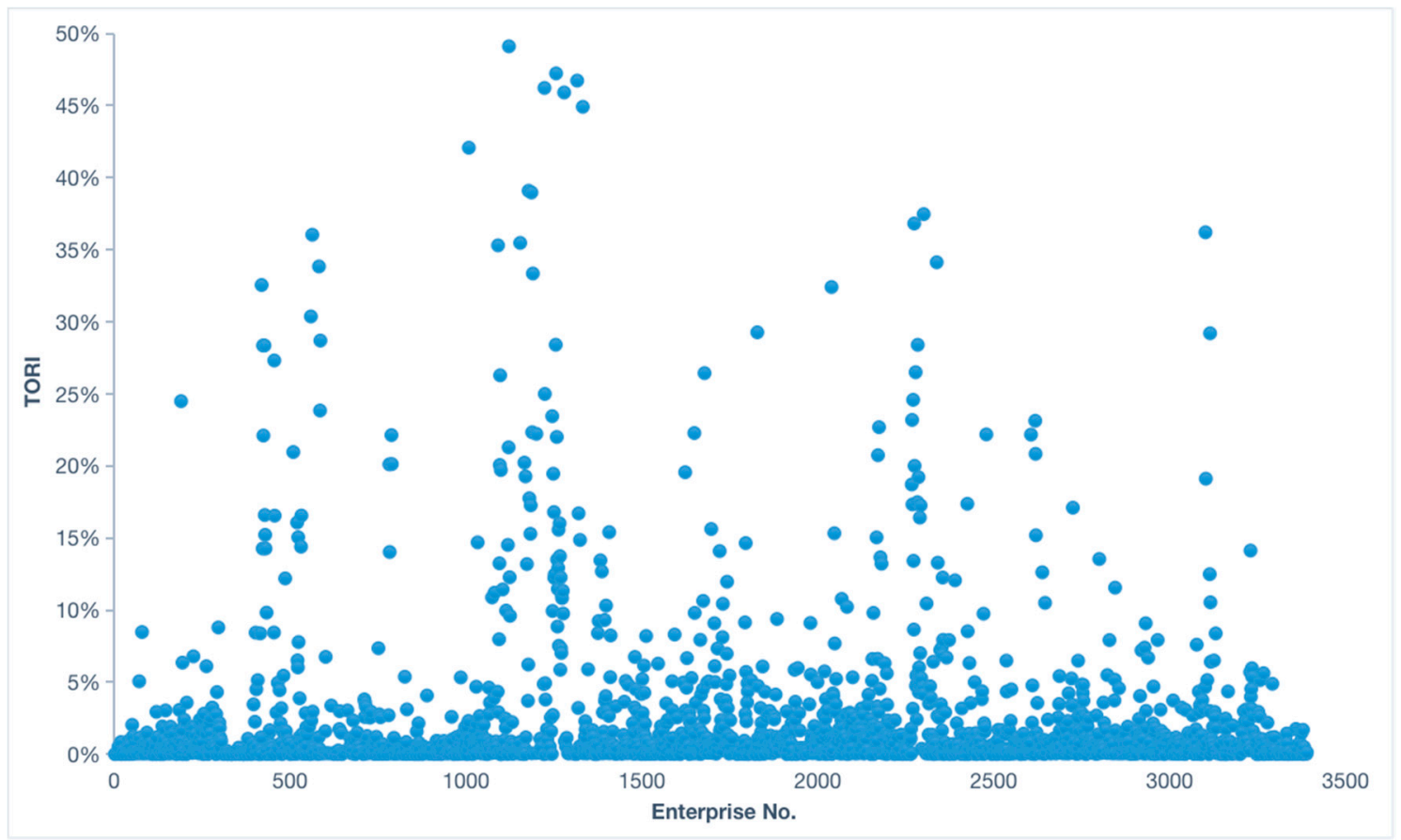

Figure 2. Scatter diagram of tax-output ratio impact (TORI) under the low scenario.

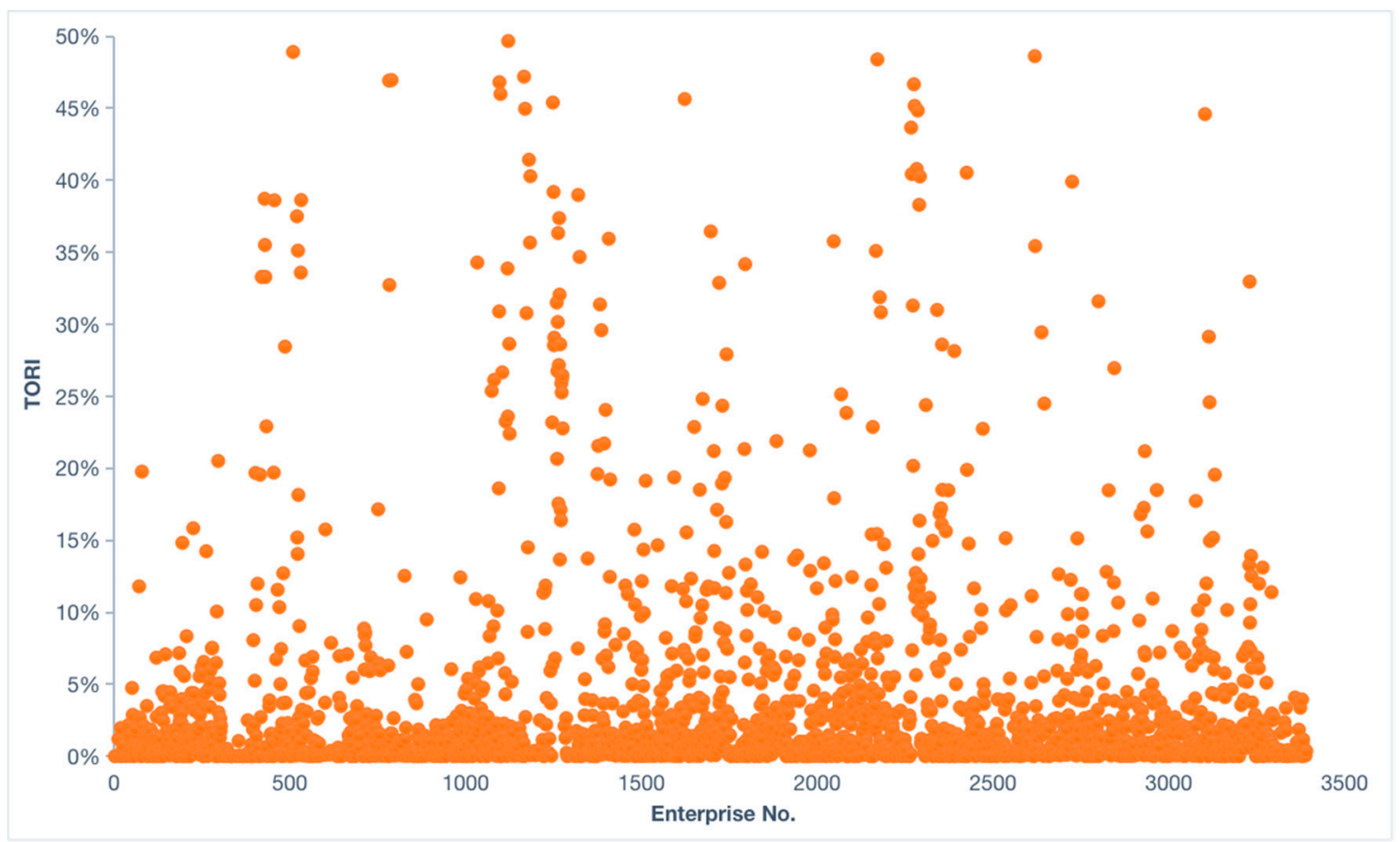

Figure 3. Scatter diagram of TORI under the medium scenario. 


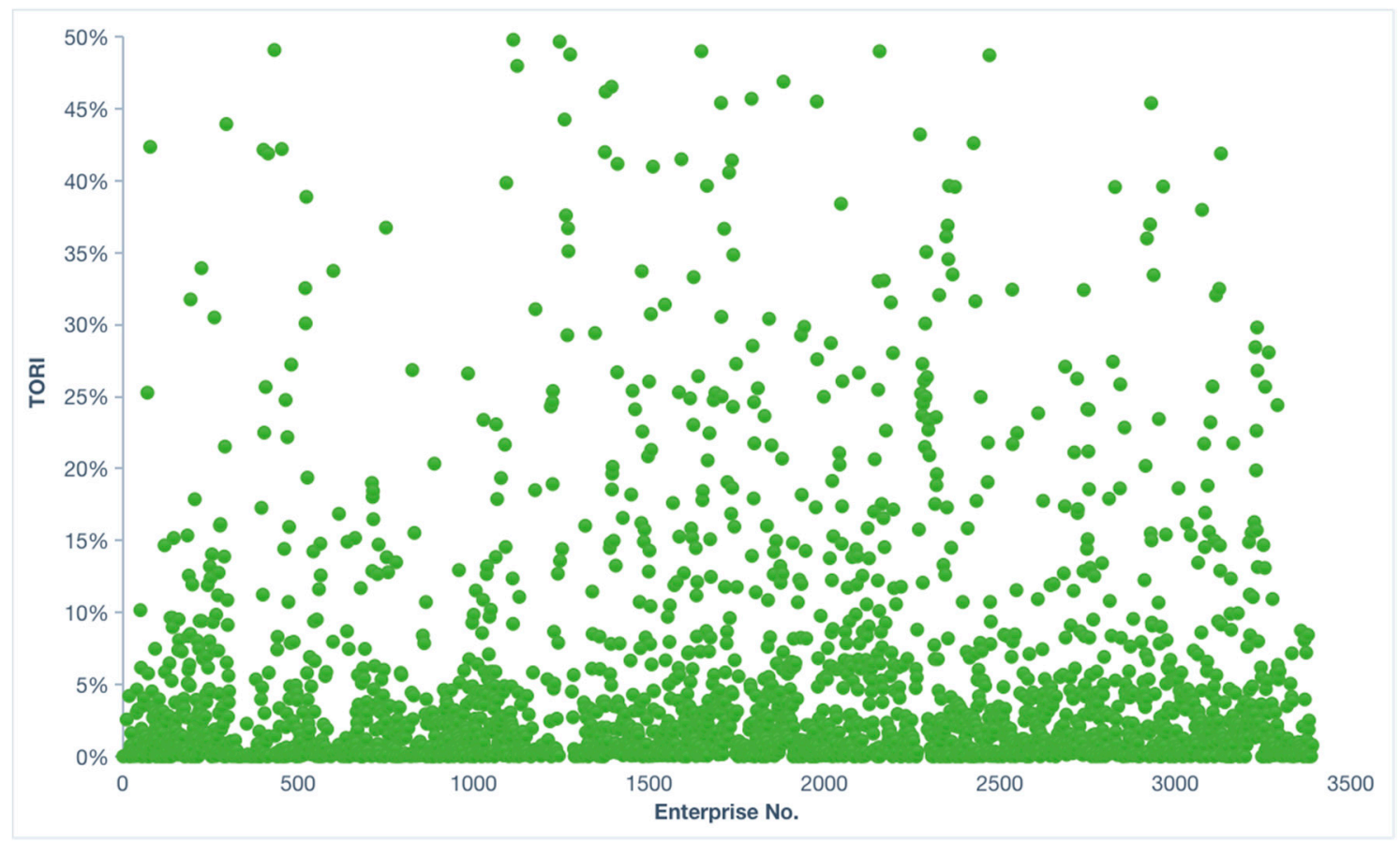

Figure 4. Scatter diagram of TORI under the high scenario.

Table 4. Evaluation of the TORI of pollutant-discharge units under low, medium and high scenarios.

\begin{tabular}{|c|c|c|c|c|c|c|c|c|c|}
\hline Classification & TORI & $\begin{array}{l}\text { Distribution of } \\
\text { Pollutant-Discharge } \\
\text { Units under the } \\
\text { Low Scenario }\end{array}$ & $\begin{array}{l}\text { Percentage of } \\
\text { Total Samples }\end{array}$ & $\begin{array}{c}\text { Distribution of } \\
\text { Sewage Units } \\
\text { under the } \\
\text { Medium Scenario }\end{array}$ & $\begin{array}{l}\text { Percentage of } \\
\text { Total Samples }\end{array}$ & $\begin{array}{c}\text { Low and } \\
\text { Medium Plan } \\
\text { Change Rate }\end{array}$ & $\begin{array}{l}\text { Distribution of } \\
\text { Pollutant-Discharge } \\
\text { Units under the } \\
\text { High Scenario }\end{array}$ & $\begin{array}{l}\text { Percentage of } \\
\text { Total Samples }\end{array}$ & $\begin{array}{l}\text { Medium and } \\
\text { High Plan } \\
\text { Change Rate }\end{array}$ \\
\hline First level & $<1 \%$ & 1284 & $37.9 \%$ & 959 & $28.3 \%$ & $-25.3 \%$ & 365 & $13.7 \%$ & $-44.0 \%$ \\
\hline Second level & $1 \%-1.5 \%$ & 1426 & $42.1 \%$ & 1377 & $40.6 \%$ & $-3.4 \%$ & 957 & $28.2 \%$ & $-17.2 \%$ \\
\hline Third level & $1.5 \%-3 \%$ & 237 & $7.0 \%$ & 374 & $11.0 \%$ & $57.8 \%$ & 361 & $10.6 \%$ & $-8.6 \%$ \\
\hline Fourth level & $3 \%-5 \%$ & 137 & $4.0 \%$ & 167 & $4.9 \%$ & $21.9 \%$ & 278 & $8.2 \%$ & $-12.0 \%$ \\
\hline Fifth level & $5 \%-10 \%$ & 119 & $3.5 \%$ & 207 & $6.1 \%$ & $73.9 \%$ & 387 & $11.4 \%$ & $30.3 \%$ \\
\hline Six level & $>10 \%$ & 187 & $5.5 \%$ & 306 & $9.0 \%$ & $63.6 \%$ & 942 & $27.8 \%$ & $64.1 \%$ \\
\hline
\end{tabular}


From the specific inventory of the TORI of each pollutant-discharge unit under the low, medium and high scatter diagrams and proportion of TORI of each pollutant-discharge unit under low, medium and high scenarios, shown in Table 4. We find that, under the low scenario, there are 2710 enterprises with low TORI (less than 1.5\%), accounting for $80 \%$ of the total sample and 306 companies with high TORI (above $5 \%$ ), accounting for $9.0 \%$ of the total sample. Under the medium scenario, the number of enterprises with low TORI is 2336 , accounting for $68.9 \%$ of the total sample and 513 companies with a high TORI accounting for $15.1 \%$ of the total sample. Under the high scenario, the number of enterprises with low TORI decrease significantly, with a total of 1322, accounting for $41.9 \%$ of the total sample number and the number of enterprises with high TORI is 1329 , accounting for $39.2 \%$ of the total sample number. At the same time, from the perspective of the change rate, compared with medium scenario, the amount of environmental taxpayer to the high scenario decreases by $44.0 \%$ and the enterprises with high TORI increase by $64.1 \%$.

\section{Discussion}

\subsection{Discussion of Scenario Analysis}

\subsubsection{Low Environmental Tax Rate Scenario}

When the environmental tax is set at low level, the collection of environmental taxes is the same as environmental tax rate standard of 2018 and the pollutant-discharge fee standard of 2017. It is estimated that 224 million yuan will be levied, but 213 million yuan levied in reality in 2018 [28]. Environmental taxes are mainly based on air pollutants, accounting for $91.13 \%$ of the province's environmental tax revenue and sewage, noise and solid waste environmental tax revenues account for $3.70 \%, 4.90 \%$ and $0.27 \%$ of the total, respectively. The environmental tax revenue of atmospheric emissions and sewage in key industries accounts for $68.88 \%$ of the province's environmental tax revenue. Key industries with annual tax payments of tens of millions of yuan include the non-metallic mineral products industry; ferrous metal smelting and rolling; chemical raw materials and chemical products' manufacturing; non-ferrous metal smelting and rolling processing; and electricity, heat production and supply. Low tax rates exert only a certain amount of pressure on the electric power, heat production and supply industry, but are not enough to motivate companies to carry out further emission reduction actions on their own. For others, the cost of governance is still much higher than is the cost of paying taxes. When the emission standard is reached, direct discharge of pollutants becomes the optimal decision and companies will pay environmental taxes directly to reduce costs.

\subsubsection{Medium Environmental Tax Rate Scenario}

When the environmental tax levy rate is at the medium level, the fiscal revenue of environmental tax is expected to be approximately 560 million yuan. It is estimated that the provincial environmental tax revenue in 2019 will account for $0.267 \%$ of the local fiscal public budget revenue of Yunnan Province in 2019. Environmental tax revenues from atmospheric emissions and sewage in key industries account for approximately $70.70 \%$ of the province's environmental tax revenues. In addition to the 10 million yuan taxation industry under the low scenario, the taxes on the mining industry, the petroleum processing industry and the coking and nuclear fuel processing industries will also exceed 10 million yuan. Under this scenario, industries that have a greater incentive to reduce water pollution include the chemical raw materials and chemical products manufacturing industry; the non-ferrous metal smelting and rolling processing industry; the electricity, heat production and supply industry; the agricultural and sideline food processing industry and the agriculture, forestry, animal husbandry and fishery services; the food manufacturing industry; the liquor, beverage and refined tea manufacturing industry; and the nuclear fuel processing industry. Theoretically, the environmental tax reduction and exemption obtained by the above types of enterprises will be greater than the cost of emission reduction, and a 
certain degree of technological transformation will be selected to reduce pollution emissions and maximize corporate benefits.

\subsubsection{High Environmental Tax Rate Scenario}

When the environmental tax levy rate is high, the tax amount of the paper and paper products industry will also exceed 10 million yuan. At the same time, the tax rate standard will approach the marginal pollution control costs of most industries, which will have a significant impact on most industries and encourage many companies to transform and upgrade their technology to increase their pollution reduction efforts. However, it must also be noted that this will obviously challenge the normal production and operation of high-pollution, high-energy-consumption and high-emission, but low-efficiency enterprises, and a little carelessness may lead to a significant impact on regional economic development and local employment.

\section{Conclusions and Policy Recommendations}

\subsection{Conclusions}

At present, most of the studies on tax payment are focused on the national level and studies at the local level, such as the provincial level, are lacking. For China, which has just implemented the policy of environmental tax, there has been almost no research on environmental tax for the less developed provinces and regions in the western part of the country. This study selected Yunnan Province, China, as a case study, collected pollution emission data and used the governance cost method to estimate costs, and processed the data using boxplot methods. The results show that the current environmental tax rate is quite different from the cost of corporate environmental governance. The cost difference is significant. Therefore, this study draws the following main conclusions:

(1) The scope of environmental tax coverage is narrow. According to the identification data of the second pollution census in Yunnan Province [29], as of 30 June 2018, there are 50,628 pollutant-discharge companies operating in Yunnan Province, which is far from the number of more than 4000 taxpayers currently involved in environmental tax. This reflects that the number of polluting enterprises included in the scope of environmental tax collection and management is obviously insufficient, which limits the role of environmental tax in guiding enterprises to reduce pollution and further promote the improvement of overall environmental quality. At the same time, there are 12,731 large-scale livestock and poultry farms in Yunnan, as well as a large number of agricultural pollutants. The amount of pollutants discharged is large, causing huge non-point source pollution, but no tax is currently collected.

(2) Environmental tax places a heavy burden on some industries. From the perspective of the industry, such as ferrous metal smelting and rolling processing, non-ferrous metal smelting, non-metallic mineral processing, paper making, manufacturing, chemicals, furniture manufacturing, coal mining, metal products and agricultural and sideline products processing, they account mainly of the tax revenue. Although the environmental tax has placed a small tax burden on most enterprises, it has put great pressure on the production and operation of non-ferrous metals, steel, thermal power and other heavy industrial enterprises. After the increase of the environmental tax rate in 2019, the environmental tax burden of these enterprises will be heavier. The non-ferrous metals, steel, thermal power and other industries that already find it difficult to make a profit will face greater pressure for survival, and these enterprises often bear the important responsibility of local employment stability.

(3) Monitoring and verification costs are high. Most taxpayers only entrust a third-party monitoring agency to conduct pollution source monitoring for half a year, one year or even two years, which makes it difficult to meet the requirements of environmental tax collection. If these companies are required to provide all quarterly monitoring data, they will face the pressure of high pollution source monitoring costs. The survey results show that some companies entrust a 
third party to conduct monitoring once per year, and the monitoring cost is tens of thousands of yuan, whereas the environmental protection tax paid every quarter is only tens or hundreds of yuan; thus, the cost of monitoring is generally much greater than is the amount of tax paid.

Based on the above reality, more refined environmental tax management policies is needed in the future. Not only will pollutants be divided into the categories of water, gas, sound and slag, but also they will be actively explored from the perspective of the industry. Different environmental taxes will be imposed on different categories of industries. At the same time, multiple methods to improve tax compliance have been studied, including efforts to either use incentives or strengthen supervision and simplify the collection process, so that environmental taxes can effectively reduce pollutant emissions.

\subsection{Policy Recommendations}

Based on the outcomes of the study, policy recommendations are given below:

(1) Gradually increase the level of environmental tax rate. Because the environmental tax policy in Yunnan Province is derived from the transform of pollutant-discharge fee to environmental tax and the previous pollutant-discharge fee data have been studied and analyzed, it is concluded that the current enterprises' promotion of environmental protection and emission reduction is still based mainly on administrative orders. The environmental tax rate is significantly lower. However, considering the impact of a large-scale increase of the environmental tax rate on heavy industrial enterprises that absorb a lot of employment, we should gradually increase the environmental tax rate to a high rate scenario according to the types of pollutants and also to the regional environmental quality changes and the science and technology development level. The tax rate should be adjusted year by year so that the final actual emission reduction is equal to the expected emission reduction and the total social cost is the lowest.

(2) Increase efforts to compensate enterprises for environmental protection. The current level of tax rates is not high, and the cost of related technological transformation inputs is much higher than are tax incentives. To achieve the double dividend of environmental tax and the Porter Hypothesis, in addition to obtaining more fiscal revenue by increasing tax rate, greater efforts should be made to strengthen tax rebates. Corporate income tax reductions should be made for corporate environmental protection investments. The subsidy for the purchase of enterprise equipment really achieves the effect of encouraging enterprises to innovate technologies to achieve green taxation through energy saving and emission reduction. With reference to the nitrogen emission tax implemented by Sweden in 1992, a tax rate has been set that is far higher than that of the OECD countries during the same period [22]. The tax is levied on the basis of the amount of pollutant-discharge, but the government does not intercept this part of the tax and instead uses the energy production as the basis for the tax refund. All taxes are returned to the taxpayers. This actually rewards companies with small unit energy emissions and punishes companies with high unit energy emissions, thus providing incentives to reduce unit energy production emissions. This measure has significantly reduced the unit energy production emissions in Sweden. In fact, the benefit obtained from this plan is three times the cost of abatement. Therefore, China can increase the environmental tax rate while subsidizing the excessive tax collection from the emission reduction companies, so that their product costs are at the same level as are those of highly polluting enterprises and avoid the competitiveness of emission reduction companies due to rising operating costs.

(3) Strengthen tax supervision to achieve tax fairness. The principle of tax fairness is considered to be the first principle of the design and implementation of the modern tax system. Under the same circumstances, different taxpayers bear different levels of tax burdens, and increasing the number of taxpayers who pay more taxes will inevitably generate resistance, thereby breeding tax evasion behaviors. At the same time, to avoid tax evasion, enterprises in the production and operation process will be affected by product production. The cost is low, bad currency 
expels good currency, and the emission reduction enterprise suffers. Thus, the tax system design and the fairness of the implementation of tax policy will directly affect the tax compliance of taxpayers [30]. Therefore, the government can explore the formation of a joint inspection team of tax Bureau and environmental protection department; strengthen the information interaction and joint law enforcement of environmental tax related departments; increase tax collection, reduction and exemption for information disclosure; encourage the public to supervise and report on polluting enterprises; severely punish enterprises that evade environmental taxes and other taxes; improve the tax compliance of environmental taxpayers; and promote tax fairness [31].

Author Contributions: B.H. is responsible for writing article; H.D. is responsible for data collection and processing; P.J. provides guidance for article writing and provides assistance in data collection; J.Z. assists in receipt collection and processing. All authors have read and agreed to the published version of the manuscript.

Funding: The research was funded by the National Natural Science Foundation of China (Grant No.: 71774033) and Fudan Tyndall Center of Fudan University (Grant No.: IDH6286315).

Acknowledgments: We would like to thank the supports from the founders and also thank the editor and reviewers for their valuable comments to improve this work.

Conflicts of Interest: The authors declare no conflict of interest.

\section{References}

1. Van Donkelaar, A.; Martin, R.V.; Brauer, M.; Kahn, R.; LevyiD, R.; Verduzco, C.; Villeneuve, P.J. Global estimates of ambient fine particulate matter concentrations from satellite-based aerosol optical depth: Development and Application. Environ. Heal. Perspect. 2010, 118, 847-855. [CrossRef]

2. Li, R.; Ramanathan, R. Exploring the relationships between different types of environmental regulations and environmental performance: Evidence from China. J. Clean. Prod. 2018, 196, 1329-1340. [CrossRef]

3. Shen, N.; Liao, H.; Deng, R.; Wang, Q. Different types of environmental regulations and the heterogeneous influence on the environmental total factor productivity: Empirical analysis of China's industry. J. Clean. Prod. 2019, 211, 171-184. [CrossRef]

4. Zhao, Y.M. Research on the definition, classification and evolution of environmental regulations. China Popul. Resour. Environ. 2009, 12, 89-94. (In Chinese)

5. Qin, C.B. Economic and emission impact analysis of reforming China's environmental taxes system. China Popul. Resour. Environ. 2015, 173, 19-25. (In Chinese) [CrossRef]

6. Qu, G.P. Review and thinking of China's environmental protection for forty years. Environ. Prot. 2013, 41, 10-17. (In Chinese)

7. Chinese Central Government. Regulations on the Administration of Collection of Pollution Charges. 2003. Available online: http://www.gov.cn/gongbao/content/2003/content_62565.htm (accessed on 21 May 2020).

8. Zhou, Y. Development history and literature review of environmental tax. Decis. Inf. Mag. 2012, 4, 188-189. (In Chinese)

9. Tullock, G. Excess benefit. Water Resour. Res. 1967, 3, 643-644. [CrossRef]

10. Bovenberg, A.L.; Mooij, R.A.D. Environmental tax reform and endogenous growth. J. Public Econ. 1994, 63, 207-237. [CrossRef]

11. Pearce, D. The role of carbon taxes in adjusting to global warming. Econ. J. 1991, 101, 938. [CrossRef]

12. Bossier, F.; Brechet, T. A fiscal reform for increasing employment and mitigating $\mathrm{CO}_{2}$ emissions in europe. Energy Policy 1995, 23, 789-798. [CrossRef]

13. Van Heerden, J.; Gerlagh, R.; Blignaut, J.; Horridge, M.; Hess, S.; Mabugu, R.; Chitiga-Mabugu, M. Searching for triple dividends in South Africa: Fighting $\mathrm{CO}_{2}$ pollution and poverty while promoting growth. Energy J. 2006, 27, 113-141. [CrossRef]

14. Liu, H.M.; Sun, M.X.; Wang, H.L.; Wang, K.Q. Summary of the research on the "double dividend" of environmental tax. Tax Res. 2007, 7, 82-87. (In Chinese)

15. Jin, S.L. The international experience of environmental taxation and the basic conception of China's environmental taxation. Rev. Econ. Res. 2007, 58, 53-56. (In Chinese) [CrossRef]

16. Li, H.X.; Fu, B.Y. General equilibrium analysis and application model of environmental tax. China Popul. Resour. Environ. 2004, 14, 21-24. (In Chinese) 
17. Gallego, B.; Lenzen, M. A consistent input-output formulation of shared producer and consumer responsibility. Econ. Syst. Res. 2005, 17, 365-391. [CrossRef]

18. Lenzen, M.; Murray, J.; Sack, F.; Wiedmann, T. Shared producer and consumer responsibility-theory and practice. Ecol. Econ. 2007, 61, 27-42. [CrossRef]

19. Peters, G.P. From production-based to consumption-based national emission inventories. Ecol. Econ. 2008, 65, 13-23. [CrossRef]

20. Liang, S.; Stylianou, K.S.; Jolliet, O.; Supekar, S.D.; Qu, S.; Skerlos, S.J.; Xu, M. Consumption-based human health impacts of primary PM2.5: The hidden burden of international trade. J. Clean. Prod. 2017, 167, 133-139. (In Chinese) [CrossRef]

21. Wang, Z.H. Development trend and policy implications of OECD environmental tax. Int. Tax. China 2017. (In Chinese) [CrossRef]

22. Tom, T. Ethical influences on the evolution of the US tradable permit approach to air pollution control. Ecol. Econ. 1998, 24, 241-257. [CrossRef]

23. Cao, D. Economics of Industrial Pollution in China; China Environment Press: Beijing, China, 1999; pp. $96-97$. (In Chinese)

24. Wang, A.J.; Lin, J.; Feng, K.; Liu, P.; Du, M.; Ni, R.; Chen, L.; Kong, H.; Weng, H.; Liu, M.; et al. Environmental taxation and regional inequality in China. Sci. Bull. 2019, 64, 1691-1699. [CrossRef]

25. National Bureau of Statistics. China Statistics Yearbook; China Statistics Press: Beijing, China, 2015.

26. National Bureau of Statistics. China Environmental Statistics Yearbook; China Statistics Press: Beijing, China, 2016.

27. Ge, C.Z.; Wang, J.N.G. Environmental Protection and Public Finance; China Environmental Science Press: Beijing, China, 2016.

28. China Environmental Protection News. 4 March 2019. Available online: http://sthjt.yn.gov.cn/zwxx/xxyw/ xxywrdjj/201904/t20190403_188972.html (accessed on 10 December 2019).

29. China Environmental Protection News. 4 September 2019. Available online: https://www.cenews.com.cn/ subject/2018/wrypc/a_4148/201904/t20190409_896957.html (accessed on 10 November 2019).

30. Wu, X.D.; Yao, Q.Y. Research on the issue of redemption compliance from the perspective of behavioral economics. Res. Financ. Econ. Issues 2011, 3, 84-89. [CrossRef]

31. Zhou, K.Q.; Liu, W.H. Tax compliance and law implementation: Analysis of the perfect path of environmental tax collection and management system. Friends Account. 2019, 17, 136-139. 